\title{
RHYTHMIC GYMNASTIC MOVEMENTS AND FOLKLORE DANCES IN STUDENTS' COORDINATION ABILITIES
}

\author{
Giurka Gantcheva, Magdalena Damjanovska \\ National Sports Academy "Vassil Levski" \\ First private University FON, Faculty of Sport Management
}

\begin{abstract}
Summary
Introduction

Rhythmic gymnastics requires a four-way coordination of movements: the movements of the gymnast, the apparatus manipulation, the musical accompaniment and the four partners.

The aim of the study is to perfect the coordination abilities of rhythmic gymnasts by means of some exercises and folklore dances, with musical accompaniment.

Methodology

The methods of the research include implementation of the following gymnastic movements and dances in the training: Dancing combinations - 1. Straight horo, 2. Ruchenitza, 3. Balkan peoples' dances.

Rhythmic gymnastics movement with apparatus - hoop, ball, clubs.

Testing: 1.Frontal feet and hands hitting against a wall, 2.Feet and hands hitting (in a corner), 3.Jumps in four squares, 4.Cross jumps in four squares.

Results

When studying the statistically significant results of the differences, we can notice the absolute increase of the results which is $d=4.20 ; 4.62 ; 3.64 ; 3.96$ for the respective tests. The relative increase $d \%=86.30 \% ; 83.87 \% ; 64.06 \%$ and $71.77 \%$ shows a good result as well.

Discussion

The chosen dancing steps and gymnast movement combinations correspond to the motor abilities of the researched individuals, to their spirit and culture. The musical accompaniment used conforms to the characteristic features of the dancing movements, and their combination with the movements with the rhythmic gymnastics apparatuses is a suitable method for coordination of body-apparatus-music.

Conclusions

The coordination tests show that after the implementation of the methods the greater part of the researched individuals has improved their coordination abilities. The application of the exercises and dances should be in accordance with the pulsations of the musical accompaniment.
\end{abstract}

Key words: gymnastic, dances, coordination abilities

\section{Introduction}

There are changes in rhythmic gymnastics in every Olympic cycle determined by the competitive rules which are being constantly improved. Generally, they are aimed at the development of a particular side of the competitive routines but very often their interaction practically leads to unexpected changes. In the recent years there has been a trend towards inclusion of more dance and artistic elements (Viner-Usmanova, 2015). However, the number and the difficulty of the exercises and combinations in the routines are the crucial factor for receiving high score, good ranking and medals (Gantcheva, G. 2017). The consecutive execution of a number of exercises with or without apparatus of different dynamic and cinematic structure will certainly increase the requirements to the gymnasts' coordination abil- ities (Hadjiev at al., 2011, Damjanovska at al, 2015, 2016). Moreover, the qualities speed and accuracy of execution are very important for the final score in modern rhythmic gymnastics (Hafe, 2016). In order to improve the coordination abilities in rhythm the gymnastics specialists employ the means of the folklore dance art and musical accompaniment which correspond to the gymnasts' motor abilities, to their mentality and culture (Zachopolou, et all 2004).

\section{Aim and Objectives of the study}

The aim of the study is 1) to improve the coordination abilities of rhythmic gymnasts by means of some exercises and folklore dances, with musical accompaniment; 2) to create combinations of dance steps with musical accompaniment of different rhythmical structure; 3) to combine the dance movements with 
rhythmic gymnastics exercises with apparatuses.

\section{Methods}

The methods of the research include implementation of the following gymnastics movements and dances in the training:

Dancing combinations: 1 . Straight horo; 2. Ruchenitza; 3. Balkan peoples' dances.

Rhythmic gymnastics movement with apparatus hoop, ball, clubs.

Short dance combinations with simultaneous play with the apparatuses were performed.

The research was done among 45 female students.

Testing: The following tests were used: (Damjanovska, Gontarev, Radisavljevic, 2013)

Frontal feet and hands hitting against a wall;

Feet and hands hitting (in a corner);

Jumps in four squares;

Cross jumps in four squares.

Math-statistical methods:

Variation analysis

T-criterion of Student, $d$ and d\% - for statistical significance of the differences.

\section{Results}

Variation analysis of the results

\begin{tabular}{|c|c|c|c|c|c|c|c|c|c|}
\hline Research & $\mathrm{n}$ & $\mathrm{Xmin}$ & $\mathrm{Xmax}$ & $\mathrm{R}$ & $\mathrm{X}$ & $S$ & $\mathrm{~V}$ & As & Ex \\
\hline \multicolumn{10}{|l|}{ Test -1} \\
\hline Beginning & 45 & 3 & 14 & 11 & 4.87 & 1.38 & 28.26 & 0.251 & -0.989 \\
\hline End & 45 & 6 & 14 & 8 & 9.07 & 2.22 & 24.48 & 0.434 & -0.729 \\
\hline \multicolumn{10}{|l|}{ Test - 2} \\
\hline Beginning & 45 & 2 & 16 & 14 & 5.51 & 1.22 & 22.10 & -0.383 & 0.422 \\
\hline End & 45 & 6 & 16 & 10 & 10.13 & 2.27 & 22.42 & 0.703 & -0.009 \\
\hline \multicolumn{10}{|l|}{ Test -3} \\
\hline Beginning & 45 & 4 & 12 & 8 & 5.69 & 1.18 & 20.81 & 0.386 & -0.943 \\
\hline End & 45 & 7 & 12 & 5 & 9.33 & 1.41 & 15.15 & 0.381 & -0.42 \\
\hline \multicolumn{10}{|l|}{ Test -4} \\
\hline Beginning & 45 & 2 & 13 & 11 & 5.51 & 1.22 & 22.10 & -0.383 & 0.422 \\
\hline End & 45 & 7 & 13 & 6 & 9.47 & 1.55 & 16.33 & 0.509 & -0.556 \\
\hline
\end{tabular}

Table 2

\section{Statistical significance of the increase in the results}

\begin{tabular}{|l|l|l|l|l|l|l|l|l|l|}
\hline \multirow{2}{*}{ Index } & \multirow{3}{*}{$\mathrm{n}$} & \multicolumn{4}{|l|}{ Beginning } & \multicolumn{5}{|l|}{ End } & \multicolumn{4}{l|}{$\begin{array}{l}\text { Statistical significance of } \\
\text { the results }\end{array}$} \\
\cline { 3 - 10 } & & $\mathrm{X} 1$ & $\mathrm{~S} 1$ & $\mathrm{X} 2$ & $\mathrm{~S} 2$ & $\mathrm{~d}$ & $\mathrm{~d} \%$ & $\mathrm{t}$ & $\mathrm{P}(\mathrm{t})$ \\
\hline Test -1 & 45 & 4.87 & 1.38 & 9.07 & 2.22 & 4.20 & 86.30 & 14.63 & 100.00 \\
\hline Test -2 & 45 & 5.51 & 1.22 & 10.13 & 2.27 & 4.62 & 83.87 & 15.75 & 100.00 \\
\hline Test -3 & 45 & 5.69 & 1.18 & 9.33 & 1.41 & 3.64 & 64.06 & 13.41 & 100.00 \\
\hline Test -4 & 45 & 5.51 & 1.22 & 9.47 & 1.55 & 3.96 & 71.77 & 20.76 & 100.00 \\
\hline
\end{tabular}

The results from the variation analysis for Test №1 -

Frontal feet and hands hitting against a wall are presented in table 1 . The minimum values change their number but the maximal ones remain stable at the end of the research. The improvement of the results is due to the increased number in the minimum values. The range $(\mathrm{R}=11, \mathrm{R}=8)$ confirms this conclusion. The researched individuals find it easy to perform simultaneous actions with upper and lower limbs because this is one of the characteristics of the motor activities they practise. The obligatory rhythm of the performance, due to the observance of the rhythmical structure of the musical accompaniment when performing dance steps, supports significantly the synchronization of the motor actions. The values of $X$ mean $=9.07$ at the end of the research are indicative of a good result. But probably the circumstance that the movements are executed in the opposite manner is troublesome when performing the test. The gymnasts have skills and habits to work with both arms, but the possibilities of the two sides (left and right) remain different.

The sample in both tests is homogeneous since the coefficient of variation in the first test is $\mathrm{V}=$ $28.26 \%$, and in the second $\mathrm{V}=24.48 \%$. The results from the statistical significance of the differences are shown in table 2 . The value of the absolute increase of the results is $\mathrm{d}=4.20$, and the relative share $-\mathrm{d} \%=86.30 \%$. These are two results which confirm the positive sides of the methods we used.

The minimum value in the first research is $\mathrm{X}$ min $=2$ cycles, and the maximal value is with 14 cycles more than the minimum one, therefore $\mathrm{X} \max =$ 16 cycles. This result determines the coordination of the researched individuals as good. The coefficient of variation is $\mathrm{V}=22.10 \%$ which enables us to determine the sample as sufficiently homogeneous.

The results from the variation analysis of test №2 Feet and hands hitting - show the minimum value $\mathrm{X}$ min $=6$ cycles and we can say that the increase of the result, compared to the first research, is due to the methods we used. The motor movements of the arms are subjected to the rhythm of the movements of the lower limbs. The work with small portable apparatuses assists their improvement both from technical point of view and from coordination point of view regardless of the difference in the amplitude of the movements. The maximum value remains the same $\mathrm{X} \max =16$ cycles. The mean value is $\mathrm{X}$ mean $=10.13$, which is a 4.62 times better achievement than the initial testing. The increase of the result can be also seen in the value of the range $\mathrm{R}=4$, which means that the difference between the minimum and maximum value in the second research is lower. This is indicative of the better results of the researched individuals who had moderate results at the beginning of the period of the 
research. We cannot report for a significant change in the coefficient of variation $\mathrm{V}=22.42 \%$. Although the dispersion of the sample is bigger than that of the first test, this result shows once again that the sample is sufficiently homogeneous.

When analysing the results from the statistical significance of the differences (shown in table 2), we can see the absolute increase in the results, which is $\mathrm{d}=4.62$. The result for the relative increase is also good $\mathrm{d} \%=83.87 \%$. According to t-criterion of Student $P(t)=100.00 \%$ which means the increase in the result is statistically significant.

The results from the variation analysis of test № 3 - Cross jumps in four squares - are presented in table 1 and show that the gymnast with the lowest result has $\mathrm{X} \min =4$ cycles, and the value of the best result is $\mathrm{X} \max =12$ cycles. The minimum and maximum values are insignificantly different $-\mathrm{R}=3 \mathrm{cy}$ cles. The mean value is $\mathrm{X}$ mean $=5.69$, which shows that the results of most of the gymnasts are closer to the minimum values than to the maximum ones. The coefficient of variation is $\mathrm{V}=20.81 \%$, which is indicative of the sufficient homogeneity of the sample. When analysing the results from the second testing, we found out that the achievements were better since the requirements of the test were met and the methods we used had influenced positively most of the researched individuals.

The statistical significance of the differences is confirmed by the absolute increase in the results $\mathrm{d}=3.64$. The reported relative increase in the results is $\mathrm{d} \%=$ $64.06 \%$. The guarantee probability $\mathrm{P}(\mathrm{t})=100.00 \%$, which means that the increase in the results is statistically significant. When we take into account the values of $d, d \%$ and $P(t)$, which determine the statistical significance of the results, we can conclude that the methods we used have a positive effect.

The results from the variation analysis of test № 4 - Cross jumps in four squares - show that some of the results at the beginning of the research are of low values and do not meet the expectations. The minimum values are $\mathrm{X} \min =2$ cycles, the maximum values are $\mathrm{X} \max =7$ cycles. The range $(\mathrm{R}=$ 11 cycles at the beginning of the experiment and $\mathrm{R}$ $=6$ in the end) shows that the improvement is due to the low initial results and is a consecutive result with equal value at the end of the research. In the first testing the mean value is 5.51 , which enables us to conclude that most of the researched individuals showed results close to the minimum value. There is an increase in the mean value in the second testing $-\mathrm{X}$ mean $=9.47$, which is a 3.96 times better achievement. The sample is sufficiently homogeneous in both testings due to the mean coefficients of variation $-\mathrm{V}=22.10 \%$ in the first testing and $\mathrm{V}=$ $16.33 \%$ in the second testing.

When analysing the results from the statistical significance of the differences (shown in table 2), we can see the absolute increase in the results, which is $\mathrm{d}=3.96$. The efficiency is also confirmed by the relative increase $\mathrm{d} \%=70.77 \%$ and is probably due to the use of cross steps and back cross steps included in the dance movements of the applied methods. According to the $\mathrm{t}$-criterion of Student the guarantee probability is $\mathrm{P}(\mathrm{t})=100.00 \%$, which determined the statistical significance of the increase.

Discussion The folklore dancing steps and combinations we chose correspond to the motor abilities of the researched individuals, to their spirit and culture. The musical accompaniment used conforms to the characteristic features of the dancing movements. Their combination with the movements with the rhythmic gymnastics apparatuses is a suitable method for coordination of body-apparatus-music. Its further complication can be achieved through performance of the combinations in pairs, by three people or a bigger group. This will allow reaching an additional coordination among the participants in the group as a characteristic performance for rhythmic gymnastics. The coordination tests show that after the implementation of the methods the greater part of the researched individuals has improved their coordination abilities.

\section{References}

Gantcheva, G. (2017), Survey of the difficulty-composition relation with the ensembles in Rhythmic gymnastics, Research in kinesiology, International Journal of Kinesiology and Other Related Sciences, Federation of the Sports Pedagogues of the Republic of Macedonia, Skopje, 7-9.

Damjanovska, M., S. Gontarev, L. Radisavljevic (2013). Determination of measurement characteristics for rhythmic skills assessment tests. Conference proceedings, Effects of Physical Activity Application to Anthropological Status with Children, Youth and Adults. Univezrzitet $u$ Beogradu, Fakultet sporta I fizickog vaspitanja, 11-12 December, Beograd.

Damjanovska, M., Gontarev, S., Rhedzepi, A., Gantcheva, G. (2015). Comparing reliability and validity of 
some tests with classic and image model of assessment rhythmic ability. Sborník příspěvků $\mathrm{z}$ mezinárodní vědecké conference. Evropské Pedagogické Fórum, 2327.11. Vol. V. ISBN 978-80-87952-11-5 HardekKrálové, ČeskáRepublika.

Damjanovska, M., Gantcheva, G. Gontarev, S. (2016). The relations among Rhythmic abilities, agility, age, and sport experience length in female students of „Vasil Sport's Academy of Sofia. International Scientific Conference, Effects of Physical Activity Application to Anthropological Status with Children, Youth and Adults. Univrzitet u Beogradu, Fakultet sporta I fizichkog vaspitanja.

Hadjiev, N. at. All (2011). Gimnastika - fizicheska podgotovka. NSA Pres, Sofia. // Хаджиев и колектив, 2011. Гимнастика - физическа подготовка, [Gimnastika fizicheska podgotovka], НСА ПРЕС, София.
Hafe, R., A. (2016). Impact of coordination abilities program on accuracy and speed in rhythmic gymnastics. Science, Movement and Health, Vol. XVI, ISSUE 16 (2), 141-146.

Zachopolou, E., Tcapakidou, A., Derri, V. (2004)._e effects of a developmentally appropriate music and movement program on motor performance. Technological Educational Institution of Thessaloniki, Department of Early Childhood Care and Education, Early Childhood Research Quarterly 19, p. 631-642.

Viner-Usmanova, I. (2015), Teoria i metodika hudojestvennoi gimnastike - artistichnost i puti ee formirovania], SPORT, Moskva. // Viner-Usmanova, I. 2015. Теория и методика художественной гимнастике - артистичност и пути ее формирования. SPORT, Москва. 